\title{
On the Validity of the Group Embedded Figure Test (GEFT)
}

\author{
Mohammad Khatib \\ Faculty of Foreign Languages, Allame Tabatabaii University, Tehran, Iran \\ Email: mkhatib27@yahoo.com \\ Rasoul Mohammad Hosseinpur \\ Faculty of Foreign Languages, Qom University, Qom, Iran \\ Email: picheboun@yahoo.co.uk
}

\begin{abstract}
The cognitive styles of Field Independence/Dependence (FI/D) and the scores obtained from the Group Embedded Figure Test (GEFT) have been theoretically and empirically studied and analyzed mostly descriptively rather than critically. It has been claimed, among other things, that FIs are better at learning and using rules and prefer deductive learning. FDs, on the other hand, tend to look at the whole of a learning task and prefer inductive learning. At a personal level, it has been asserted that FI learners are mainly introvert and their FD counterparts are extrovert. This study was conducted to investigate the validity of these claims. A total of 60 adult students served as the subjects for the study. GEFT was employed to measure each student's FI/D cognitive style. An Introversion/Extroversion questionnaire was used to determine whether the subjects of the study were introvert or extrovert. Finally, a deductive and an inductive grammar Consciousness-Raising (C-R) task were utilized to determine the subjects' attitudes towards the tasks. Pearson Chi-Square test was conducted to examine the above-mentioned claims. The results showed no relationship between the learners' FI/D cognitive style and their Introvert/Extrovert variable as well as their inductive and deductive learning preference. It seems that scores on the GEFT are indicators of ability, especially in the visuo-spatial domain, rather than style measures.
\end{abstract}

Index Terms - field independence/dependence, cognitive style, introvert/extrovert, inductive/deductive consciousness-raising task, Group Embedded Figure Test

\section{INTRODUCTION}

Habieb-Mammer et al. (2001) classify the individual learning styles into three categories which are, affective, cognitive, and physiological styles. Although cognitive styles are within the realm of psychology, they are especially valuable in education, and the research on cognitive styles is applicable not only to a wide range of psychological issues, but also to education.

According to Habieb-Mammer et al. (2001) cognitive styles act as powerful variables in many educational areas such as the students' academic choices and vocational preferences, the students' continuing academic development, the students' learning and teachers' teaching and the way students and teachers interact in the classroom. Cognitive styles refer to the preferred ways individuals adopt for the perception, organization, analysis, or recollection of information and experience. They also refer to the preferred way an individual processes information. Unlike individual differences in abilities which describe peak performance, styles describe a person's typical mode of thinking, remembering or problem solving. Furthermore, styles are usually considered to be bipolar dimensions whereas abilities are unipolar. Having more of an ability is usually considered beneficial while having a particular cognitive style simply denotes a tendency to behave in a certain manner. Cognitive style is usually described as a personality dimension which influences attitudes, values, and social interaction. There are various definitions for cognitive style. Brown (1987, P. 84) defines cognitive style as: "the way we learn things in general and the particular attack we make on a problem seems to hinge on a rather amorphous link between personality and cognition". This link is referred to as cognitive style.

A number of cognitive styles have been identified and studied over the years. Field Independence (FI) versus Field Dependence (FD) is probably the most well known style. It refers to a tendency to approach the environment in an analytical, as opposed to global, fashion.

\section{REVIEW OF LITERATURE}

\section{A. Field Independent/Dependent Cognitive Styles}

During the 1970s, the literature on psychology received the new term of FI/D. FI/D cognitive styles refer to particular ways of processing information. Witkin et al. (1977) have proposed that a contrast can be made between analytic and holistic (Gestalt) individuals. When the analytic group is faced with a situation in which decision-making is necessary, 
they are more able to break a problem into its components in order to choose the components which are more significant for making the right decision and concentrate on them. To put it in other words, they have the gift to decompose a whole into constituent elements that leaves them with the opportunity to focus on, transform, and generally manipulate the constituents independently of one another. The downside to these qualities is that these people are likely to be aloof and not gregarious, which results in a less effective relationship with others (Skehan, 1998). FD individuals, on the other hand, see the world as an unanalyzed whole and do not tend to attend any part of it selectively. They are deemed to be person-oriented, interested in people and sensitive to them. Brown (1987, P. 85) defines FI as "your ability to perceive a particular, relevant item or factor in a field of distracting items". People termed FI, are more analytic, and learn effectively when confronted with a body of material to be assimilated. Brown (1987, P. 85) points out that "field may be perceptual or it may be abstract in referring to a set of thoughts, ideas, or feelings from which your task is to perceive specific relevant subsets". The FI person tends to articulate figures as discrete items from their background and to easily differentiate objects from embedding contexts. FI (or analytical) individuals have more facility with tasks requiring differentiation and analysis. Brown (1987, P. 85) defines FD style as: "the tendency to be dependent on the total field such that the parts embedded within the field are not easily perceived, though that total field is perceived more clearly as a unified whole". FD people tend to experience events globally in an undifferentiated fashion. Theses people tend to identify with a group, exhibiting a social orientation in which they are more perceptive and sensitive to social characteristics such as names and faces than are FD persons, but they are also more susceptible to external influence and more markedly affected by isolation from other people.

\section{B. Field Independent/Dependent Cognitive Styles and Language Learning}

Different studies have identified a number of connections between FI/D cognitive styles and language learning. For example, Abraham (1985, cited in Ranalli, 2001) claimed that analytic or field independent learners preferred and did better in a deductive method of learning. She concluded that subjects with the higher GEFT scores performed better on deductive learning.

Brown (1987) also proposed two hypotheses regarding the relationships of FI/D cognitive styles and language learning. In his first hypothesis he stated that field independence is closely related to classroom learning that involves analysis, attention to details, and mastering of exercises, drills, and other focused activities. Other researchers' findings provided some evidence for Brown's first hypothesis. Naiman et al. (1987) found in a study that there was a strong link between field-independence and success in the classroom. Brown (1987), in his second hypothesis, suggested that primarily FD persons will, by virtue of their empathy, social outreach, perception of other people, be successful in learning the communicative aspects of language. Abraham's findings were in line with Brown's second hypothesis, too. Brown believed that despite favoring one particular style, learners may switch to another in some circumstances. Therefore, the learners are supposed to invoke the appropriate style for the context, and teachers should try to understand the preferred style of each learner. However, it is believed that instead of developing particular cognitive style, learners should be challenged to develop a range of styles. This belief lays heavy stress on the diversification of instruction.

At a personal level, as Dornyei and Skehan (2003), Skehan (1998), and many others put it, FI learners are aloof and would prefer to find solutions to problems for themselves. These learners are not sociable and prefer to learn individually. FD learners, in contrast, are sociable and work well in groups. They are inclined to interact more and seek out more contact with other users of the second language. According to Davis (2006) field dependent individuals are typically extrovert, extrinsically motivated, and influenced by peer groups and authority figures. Field independent individuals typically possess less effective social skills, are typically introvert, intrinsically motivated, prefer competition, choice of activities, and ability to design studies and work structure.

\section{Group Embedded Figure Test (GEFT)}

Witkin and his associates (1971) have developed various pencil-and-paper tests to investigate FI/D of the learners. Group Embedded Figure Test (GEFT) is the most widely used version in the Second Language Acquisition research. According to Skehan (1998), subjects are provided with a booklet with simple visual figures embedded inside progressively more complicated visual figures. The subjects are expected to locate the hidden simple form or figure in the more complex one in a given time (12 minutes). It is supposed that those who tend to rely on external cues are less able to find the simple figures so are FD, and those who rely on internal cues are more able to find figures, hence, FI. There are 18 complex figures in the GEFT, each with an embedded simple figure. Based on the number of correct answers given by students, the scores on GEFT may range from 0 (the most FD) to 18 (the most FI). Apart from the initial booklet pages that contain rigorous directions along with some examples to illustrate the procedure for subjects, this test has three sections: The first section is intended to make students familiar with the test, and the other two parts are the body of the GEFT. The first section which has a time limit of 2 minutes includes 7 easy problems for practice, and the items in this section are not included in the total score. The real task begins at the second set and into the third one, where the test takers have to make their challenging inquiries in each 9-itemed set within the time limit of five minutes for each. Those who score above 12 out of 18 are labeled as FI and those with a score of 11 and less than 11 are branded as FD cognitive stylists. 


\section{OBJECTIVES OF THE STUDY}

GEFT has been used and is being used widely in the Second Language Acquisition research to determine learners' FI/D cognitive style. At a personal level, FI learners are aloof and would like to work individually, and FD learners are more sociable and prefer group working. In other words, FI learners are expected to be more introvert, and FD learners to be more extrovert. As a result, the primary focus of this study is to see whether there is any correlation between FI/D variable determined by GEFT and Introvert/Extrovert variable of the learners specified by personality type questionnaire of Introversion/Extroversion.

Abraham (1985, cited in Ranalli, 2001) and other researchers found correlations between field independence and a preference for deductive approaches, and field dependence and a preference for inductive learning. Thus, the secondary focus of the study is investigating Iranian learners' inductive and deductive $\mathrm{C}-\mathrm{R}$ learning preference on the basis of their FI/D cognitive style. With regard to the objectives of the study the following research questions were formed:

1 - Is there any relationship between subjects' FI/D cognitive style and the result of the Introversion/Extroversion test?

2- Is there any correlation between subjects' FI/D cognitive style and their inductive/deductive learning preference?

\section{METHOD}

\section{A. Participants}

A total of 60 adult students, 18 males and 42 females who were taking General English Course at Allame Qotb Ravandi Institute, served as the subjects for the present study. Their age ranged between 20 to 35 and they were learning English for different purposes. They were mainly university students, professional people, and housewives.

\section{B. Introversion/Extroversion Questionnaire}

In psychology two fundamentally different types of personality exist: extroverts and introverts. Extrovert is a type of personality (or behavior) that is oriented outside, for surroundings. Introvert is a type of personality (or behavior) that is oriented inside or to oneself. Most of us are introverts or extroverts by nature, but we all display either introverted or extroverted personality characteristics at different times. For instance, you may be an introvert in a group of strangers and an extrovert at home with your family. However, most people exhibit stronger tendencies one way or another, towards either the introvert or extrovert side of the spectrum.

Many different questionnaires are available in the literature through which we can find out whether we are inclined towards the introvert or extrovert side of the spectrum. In this study, the Introversion/Extroversion Questionnaire used in Douglas Brown (2001) was employed to examine research questions.

\section{Deductive and Inductive Consciousness-Raising(C-R) Task}

A grammar point suitable for the subjects of the study was selected (Relative Clause), and a deductive and inductive C-R task were designed. There are a lot of C-R tasks available in the literature of C-R (Ellis, 2002; Mohamed, 2004). Therefore, in designing the tasks a great attempt was made to closely follow their format. Both tasks were designed to be performed individually.

\section{Task Evaluation Questionnaire}

The task evaluation questionnaire was aimed at examining the learners' attitudes towards, and opinions about, the tasks. It consisted of two questions. After completing the tasks, the learners were asked to say whether they preferred to learn English grammar mostly by Method A (inductive C-R task), or Method B (deductive C-R task).

\section{E. Instrumentation}

The following steps were taken for data collection. At first, the GEFT was used to determine learners' FI/D cognitive style. The procedures for the administration of GEFT strictly followed the directions included in the manual. However, a brief explanation was added in Persian to make sure that the subjects had grasped the instructions. There were two items in the directions to illustrate the procedure. Having finished with the directions, the subjects began the first section that consisted of 7 items with a time limit of 2 minutes. As mentioned earlier, that section was only for practice, and the scores obtained were not counted in the total scoring. The researcher then gave the go-ahead for beginning the second section that included 9 items and stopped the subjects when the 5 specified minutes were over. The same procedure was then conducted with the 9-itemed third section of the booklet. Those who scored above 12 out of 18 were labeled as FI, and those with a score of 11 and less than 11 were branded as FD cognitive stylists. Then the participants were invited to take Introversion/ Extroversion test (Appendix A). This test included 15 questions. Finally, the learners were presented with an inductive and deductive grammar C-R task (Appendix B). A brief instruction was given to the students to make them familiar with these types of tasks and they became familiar with the procedures of completing the tasks. Without setting a time limit, the learners started with Method A and then proceeded on to Method B. The significant point here is that this instruction was not intended to influence the learners' preferences. Care was taken to remove the researcher from the process so that the students' preferences not be influenced by him. In all sections of the data collection, the researcher's role was limited to a facilitator. Immediately after completing inductive and deductive 
grammar C-R tasks, students were given a task evaluation questionnaire (Appendix C). They were required to select one of the choices in the questionnaire by ticking the response which was quite appropriate for them.

\section{FINDINGS}

To account for the first research question of the study, the number of FD and FI subjects was counted. As is evident from Table 5.1. below, from among 60 subjects who had participated in the study, 23 learners or $38.3 \%$ of the subjects, after taking the GEFT, were labeled FD, and 37 participants or $61.7 \%$ of the subjects were regarded as FI. From Personality Type point of view, 32 subjects or $53.3 \%$ of the participants were extrovert and 28 subjects or $46.7 \%$ of the participants were introvert. Within FD group, 13 subjects or $21.7 \%$ of the participants were extrovert and 10 subjects or $16.7 \%$ of the participants were known as introvert. Within FI group, 19 subjects or $31.7 \%$ of the participants turned out to be extrovert and 18 subjects or $30.0 \%$ of the participants were introvert.

TABLE I

COGNITIVE STYLE-PERSONALITY TYPE CROSSTABULATION

\begin{tabular}{|c|c|c|c|c|c|}
\hline & & & \multicolumn{2}{|c|}{ Personality Type } & \multirow[t]{2}{*}{ Total } \\
\hline & & & $E$ & I & \\
\hline \multirow[t]{3}{*}{ cognitive style } & FD & Count & 13 & 10 & 23 \\
\hline & & $\begin{array}{l}\text { Expected Count } \\
\% \text { within cognitive style } \\
\% \text { within Personality Type } \\
\% \text { of Total }\end{array}$ & $\begin{array}{l}12.3 \\
56.5 \% \\
40.6 \% \\
21.7 \% \\
\end{array}$ & $\begin{array}{l}10.7 \\
43.5 \% \\
35.7 \% \\
16.7 \% \\
\end{array}$ & $\begin{array}{l}23.0 \\
100.0 \% \\
38.3 \% \\
38.3 \% \\
\end{array}$ \\
\hline & FI & $\begin{array}{l}\text { Count } \\
\text { Expected Count } \\
\% \text { within cognitive style } \\
\% \text { within Personality Type } \\
\% \text { of Total }\end{array}$ & \begin{tabular}{|l|}
19 \\
19.7 \\
$51.4 \%$ \\
$59.4 \%$ \\
$31.7 \%$ \\
\end{tabular} & $\begin{array}{l}18 \\
17.3 \\
48.6 \% \\
64.3 \% \\
30.0 \%\end{array}$ & $\begin{array}{l}37 \\
37.0 \\
100.0 \% \\
61.7 \% \\
61.7 \% \\
\end{array}$ \\
\hline Total & & $\begin{array}{l}\text { Count } \\
\text { Expected Count } \\
\% \text { within cognitive style } \\
\% \text { within Personality Type } \\
\% \text { of Total }\end{array}$ & \begin{tabular}{|l|}
32 \\
32.0 \\
$53.3 \%$ \\
$100.0 \%$ \\
$53.3 \%$ \\
\end{tabular} & $\begin{array}{l}28 \\
28.0 \\
46.7 \% \\
100.0 \% \\
46.7 \% \\
\end{array}$ & $\begin{array}{l}60 \\
60.0 \\
100.0 \% \\
100.0 \% \\
100.0 \% \\
\end{array}$ \\
\hline
\end{tabular}

A Pearson Chi-Square test was conducted to examine the relationship between the learners' FI/D cognitive style and their status of being introvert and extrovert. As the following table illustrates, the result of the Pearson Chi-Square test is 0.901 which is more than 0.05 level. Therefore, we can claim that there is no relationship between learners' FI/D cognitive style and their personality type of being introvert or extrovert.

TABLE II

CHI-SQUARE TESTS

\begin{tabular}{|l|r|r|r|r|r|}
\hline & \multicolumn{1}{|c|}{ Value } & df & Asymp. Sig. (2-sided) & Exact Sig. (2-sided) & Exact Sig. (1-sided) \\
\hline Pearson Chi-Square & $.152(\mathrm{~b})$ & 1 & .696 & & \\
Continuity Correction(a) & .015 & 1 & .901 & \\
Likelihood Ratio & .153 & 1 & .696 & .793 & \\
Fisher's Exact Test & & & & & \\
N of Valid Cases & & & & & \\
\end{tabular}

In order to investigate the second research question of the study, it was felt necessary to inspect closely the FI/D learners' task preference. The following table speaks for itself: 
TABLE III

COGNITIVE STYLE-TASK TYPE CROSSTABULATION

\begin{tabular}{|c|c|c|c|c|c|}
\hline & & & \multicolumn{2}{|c|}{ Task type } & \multirow[t]{2}{*}{ Total } \\
\hline & & & A & $\mathrm{B}$ & \\
\hline \multirow[t]{7}{*}{ cognitive style } & FD & Count & 6 & 17 & 23 \\
\hline & & $\begin{array}{l}\text { Expected Count } \\
\% \text { within cognitive style } \\
\% \text { within Task type } \\
\% \text { of Total }\end{array}$ & $\begin{array}{l}7.7 \\
26.1 \% \\
30.0 \% \\
10.0 \%\end{array}$ & $\begin{array}{l}15.3 \\
73.9 \% \\
42.5 \% \\
28.3 \% \\
\end{array}$ & $\begin{array}{l}23.0 \\
100.0 \% \\
38.3 \% \\
38.3 \%\end{array}$ \\
\hline & FI & Count & 14 & 23 & 37 \\
\hline & & Expected Count & 12.3 & 24.7 & 37.0 \\
\hline & & $\%$ within cognitive style & $37.8 \%$ & $62.2 \%$ & $100.0 \%$ \\
\hline & & $\%$ within Task type & $70.0 \%$ & $57.5 \%$ & $61.7 \%$ \\
\hline & & $\%$ of Total & $23.3 \%$ & $38.3 \%$ & $61.7 \%$ \\
\hline \multirow{5}{*}{\multicolumn{2}{|c|}{ Total }} & Count & 20 & 40 & 60 \\
\hline & & Expected Count & 20.0 & 40.0 & 60.0 \\
\hline & & $\%$ within cognitive style & $33.3 \%$ & $66.7 \%$ & $100.0 \%$ \\
\hline & & $\%$ within Task type & $100.0 \%$ & $100.0 \%$ & $100.0 \%$ \\
\hline & & $\%$ of Total & $33.3 \%$ & $66.7 \%$ & $100.0 \%$ \\
\hline
\end{tabular}

As it is evident from the above table, from among 23 FD participants, 6 subjects or $10.0 \%$ of the FD learners preferred task A and 17 subjects or $28.3 \%$ of them selected task B. From among 37 subjects who were branded as FI, 14 subjects or $23.3 \%$ of the FI subjects favored task A and 23 participants or $38.3 \%$ of them selected task B. A Pearson Chi-Square test was conducted to examine the relationship between the learners' FI/D cognitive style and their inductive and deductive C-R task preference. As the following table illustrates, the result of the Pearson Chi-Square test is 0.511 which is more than 0.05 level. Therefore, we can state that the learners' FI/D cognitive style had no effect on their task preference.

TABLE IV

CHI-SQUARE TESTS

\begin{tabular}{|l|l|l|l|l|l|}
\hline & Value & df & $\begin{array}{l}\text { Asymp. Sig. } \\
\text { (2-sided) }\end{array}$ & $\begin{array}{l}\text { Exact Sig. } \\
\text { (2-sided) }\end{array}$ & $\begin{array}{l}\text { Exact Sig. } \\
\text { (1-sided) }\end{array}$ \\
\hline Pearson Chi-Square & $.881(\mathrm{~b})$ & 1 & .348 & & \\
Continuity Correction(a) & .432 & 1 & .511 & & \\
Likelihood Ratio & .898 & 1 & .343 & .408 & .257 \\
Fisher's Exact Test & 60 & & & & \\
N of Valid Cases & 60 & & & & \\
\hline
\end{tabular}

\section{CONCLUSION AND DISCUSSION}

In recent years there have been several issues in applied linguistics which have provoked quite radical disagreements. Although we are inclined to be in awe of well-known scholars and usually find it difficult to challenge their ideas, past experience has taught us that sometimes scholars, even the best known ones, are fallible. Likewise, we should appreciate that uncertainty is part of academic life, at least in the humanities, and achieving consensus is not always what we desire. Controversies are sometimes opportunities for ongoing and further development.

In the light of the results of this limited study, it does not seem advisable to make strong claims. Research, on larger scales, should be replicated and conducted so that more consistent and reliable information become available. However, some cautious conclusions might be drawn: GEFT is one of many measures of mental ability, not cognitive style.

The concept of cognitive style has been theoretically and empirically studied and analyzed mostly descriptively rather than critically for more than four decades now, and the cognitive styles of FI/D have been shown in a number of studies to be related to second language learning. Field independence/dependence typically are referred to as variables of cognitive style and believed to affect the process of perception, thinking, and problem solving. A field independent person perceives analytically, while a field dependent person perceives holistically. FIs are better at learning and using rules and prefer deductive learning. FDs, on the other hand, tend to look at the whole of a learning task which contains many items and prefer inductive learning. At a personal level, it has been claimed that FI learners are introvert and their FD counterparts are extrovert. But the result of this study does not support these claims because no correlation was found between subjects' FI/D cognitive style and the result of Introversion/Extroversion test and their inductive/deductive learning preference. It seems that scores on the GEFT are indicators of ability, especially in the visuo-spatial domain, rather than style measures and we should try to find their relationship with general intelligence and as Griffiths and Sheen (1992) put it, FI/D does not have any relevance for second language learning.

\section{APPENDIX A EXTROVERSION/INTROVERSION TEST}


Take the following self-test and score yourself according to the directions at the end. You must circle either a or b, even if you have a hard time placing yourself into one or the other.
1. I usually like ......
a. mixing with people
b. working alone
2. I'm more inclined to be.....
a. fairly reserved
b. pretty easy to approach
3. I'm happiest when I'm .....
a. alone
b. with other people
4. At a party, I ...
a. interact with many, including strangers.
b. interact with a few people I know.
5. In my social contacts and groups, I usually ....
a. fall behind on the news.
b. keep abreast of what's happening with others.
6. I can usually do something better by ....
a. figuring it out on my own.
b. talking with others about it.

7. My usual pattern when I'm with other people is to .....

a. be open and frank, and take risks.

b. keep to myself and not be very open.

8. When I make friends, usually ......

a. someone else makes the first move.

b. I make the first move.

9. I would rather .......

a. be at home on my own.

b. go to a boring party.

10. Interaction with people I don't know

a. stimulates and energizes me.

b. taxes my reserves.

11. In a group of people, I usually

a. wait to be approached.

b. initiate conversation.

12. When I'm by myself, I usually feel a sense of .......

a. solitude and peacefulness.

b. loneliness and uneasiness.

13. In a classroom situation, I prefer .....

a. group work, interacting with others.

b. individual work.

14. When I get into a quarrel or argument, I prefer to .....

a. remain silent, hoping the issue resolve itself or blow over.

b. "have it out" and settle the issue then and there.

15. When I try to put deep or complex thought into words, I usually .....

a. have quite a hard time. 
b. do so fairly easily.

Scoring procedure: Mark an X corresponding to your choices in the grid below.

\begin{tabular}{|l|l|l|}
\hline & a & b \\
\hline 1 & & \\
\hline 4 & & \\
\hline 7 & & \\
\hline 10 & & \\
\hline 13 & & \\
\hline \multicolumn{2}{|l|}{ Total } & \multicolumn{2}{l|}{} \\
\cline { 2 - 3 } &
\end{tabular}

\begin{tabular}{|l|l|l|}
\hline & a & $\underline{\mathbf{b}}$ \\
\hline 2 & & \\
\hline 5 & & \\
\hline 8 & & \\
\hline 11 & & \\
\hline 14 & & \\
\hline \multicolumn{2}{|c|}{} \\
\hline
\end{tabular}

\begin{tabular}{|l|l|l|}
\hline & a & $\underline{b}$ \\
\hline 3 & & \\
\hline 6 & & \\
\hline 9 & & \\
\hline 12 & & \\
\hline 15 & & \\
\hline \multicolumn{3}{|c|}{$=$} \\
\multicolumn{2}{c}{$=$} \\
\end{tabular}

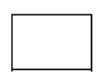

Add up the number of Xs in ONLY three of the columns, as indicated. (Ignore all other Xs). Total those three numbers to get a grand total and write it in the box at the right. This is your score for the test. Here's how to interpret your score:

13 and above: quite extroverted

9 to 12 : moderately extroverted

7 or 8 : moderately introverted

6 and below: quite introverted

\section{ApPendix B Relative Clause Task (Method A)}

1. Look at the following sentences. These sentences contain relative clauses. The relative clauses are in italics, the prepositions are underlined, and the relative pronouns are in bold.

2. You need to work on these sentences carefully. Some of these sentences are correct and some of them are incorrect.

3. Why are incorrect sentences unacceptable?

4. Write down a sentence of your own for each of these rules.

A) The dictionary which is on the table is mine. (Correct)

The dictionary who is on the table is mine. (Incorrect)

The girl who is crying is my sister. (Correct)

The girl which is crying is my sister. (Incorrect)

Explanation of the incorrect sentences: The pronoun for things.

Your own sentences:

\footnotetext{
B) The boy who likes English speaks well. (Correct)

The boy who he likes English speaks well. (Incorrect)

I like flowers which bloom in spring. (Correct)

I like flowers which they bloom in spring. (Incorrect)

\section{Explanation of the incorrect sentences:}

Your own sentence:
} is used for people, and the pronoun is used

C) $\mathrm{He}$ is the person from whom I got the letter. (Correct)

$\mathrm{He}$ is the person from whom I got the letter from. (Incorrect)

The book in which you wrote is mine. (Correct)

The book in which you wrote in is mine. (Incorrect)

Explanation of the incorrect sentences: Don't use prepositions both at the and at the Of the clauses.

Your own sentence:

D) These are the books which I told you about. (Correct)

These are the books which I told you about them. (Incorrect)

The man who you were talking to is my uncle. (Correct)

The man who you were talking to him is my uncle. (Incorrect)

Explanation of the incorrect sentences: Don't use personal pronouns at the of the clause.

Your own sentence: 


\section{Relative Clause Tack (Method B)}

Read the following information about using relative clauses. Then make sentences of your own. The relative clause in each example is in italics. The prepositions are underlined. The relative pronouns are in bold.

A) If the relative pronoun is "which" or "whom", the proposition can be used either at the front of the clause or at the end of the clause.

Example: The house in which we live is pink. (Correct)

The house which we live in is pink. (Correct)

That is the person from whom I got the letter. (Correct)

That is the person whom I got the letter from. (Correct)

Now write one sentence of your own, using this rule.

B) The proposition cannot be used both at the front of the pronoun and at the end of the clause in the same sentence. Example: The girl to whom you gave the message to is not here. (Incorrect)

The girl whom you gave the message to is not here. (Correct)

The girl to whom you gave the message is not here. (Correct)

Now write one sentence of your own, using this rule.

C) If the relative pronoun is "who" or "that", the proposition cannot be placed in front of it , but will need to be used at the end of the clause.

Example: The man $\underline{\text { at }}$ who I shouted is deaf. (Incorrect)

The man who I shouted at is deaf. (Correct)

The place about that Jenny spoke is Singapore. (Incorrect)

The place that Jenny spoke about is Singapore. (Correct)

Now write one sentence of your own, using this rule.

D) Remember not to repeat pronouns in a relative clause.

Example: These are the books about which I told you it. (Incorrect)

These are the books about which I told you. (Correct)

The man who you were talking to him is my uncle. (Incorrect)

The man who you were talking to is my uncle. (Correct)

Now write one sentence of your own, using this rule.

\section{APPENDiX C TASK EVALUATION QUESTIONNAIRE}

Select one of the choices below by ticking $(\sqrt{ })$ the response which is the most appropriate for you. Also write a short explanation for your answer.

When studying grammar in class, I prefer ......

-------- to learn new grammar mostly by method A, because

--------- to learn new grammar mostly by method B, because - to learn new grammar sometimes by method $\mathrm{A}$, and sometimes by method $\mathrm{B}$, because

\section{REFERENCES}

[1] Brown, D. H. (1987). Principles of language learning and teaching (2 ${ }^{\text {nd }}$ edn.). Rowley, Mass: Prentice Hall Regents.

[2] Brown, D. H. (2001). Teaching by principles: An interactive approach to language pedagogy (2nd edn.). Pearson Education, Longman, Inc.

[3] Davis, G. A. (2006). Learning style and personality type preferences of community development extension educators. Journal of Agricultural Education 47.1, 90-99.

[4] Dornyei, Z., \& P. Skehan (2003). Individual differences in second language learning. In C. J. Doughty \& M. H. Long (eds.), The handbook of second language acquisition. Blackwell Publishing Ltd, 589-630.

[5] Ellis, R. (2002). Grammar teaching: Practice or consciousness-raising? In J. C. Richards \& W.A. Renandya (eds.), Methodology in language teaching: An anthology of current practice. Cambridge: Cambridge University Press, 167-174.

[6] Griffiths, R. \& R. Sheen. (1992). Disembedded figures in the landscape: A reappraisal of L2 research on field dependence/independence. Applied Linguistics 13, 133-147.

[7] Habieb-Mammar, H., F. Tarpin-Bernard, B. Croisile, \& M. Noir (2001). User cognitive model for adaptive interfaces. 2 International conference Nimes TIC 2000. MaHtrise des systXmes Complexes et al Relation NHmes France December 2001.

[8] Mohamed, N. (2004). Consciousness-raising tasks: A learner perspective. ELT Journal, 58, 228-237.

[9] Naiman, N., M. Frohlich, A. Todesco, \& H. H. Stern (1987). The good language learner. Research in Education, Series 7. Toronto: Ontario Institute for Studies in Education.

[10] Oltman, P. K., E. Raskin \& H. A. Witkin. (1971). Group Embedded Figure Test. Palo Alto, California: Consulting Psychologists Press. 
[11] Ranalli, J. M. (2001). Consciousness-raising versus deductive approaches to language instruction: A study of learner preferences. http://www.cels,bham,ac.uk/resources/essays/Ranalli1,pdf (accessed 7/11/2008).

[12] Skehan, P. (1998). A cognitive approach to language learning. Oxford: Oxford University Press.

[13] Witkin, H., C. Moore, D. Goodenough, \& P. Cox. (1977). Field-dependent and field-independent cognitive styles and their educational implications. Review of Educational Research 47, 1-64.

Mohammad Khatib is Assistant Professor of TEFL at Allameh Tabataba'i University in Iran. He holds a Ph.D. in TEFL (Allameh Tabataba'i University, 1999), an M.A. and a B.A. in English Literature from Tehran University (1977 and 1972 respectively).

He began teaching at Allameh in 1981 and presently offers graduate and post-graduate courses in SLA Theories, Methodology, Literature in EFL Classes and English Literature. His main areas of interest include SLA Theories, language learning strategies, culture and the integration of language and literature. He has published some articles on TEFL in Iranian Journals of Applied Linguistics. He has translated a book of short stories from famous writers of the world and published a guidebook on Shakespeare's selected sonnets.

Rasoul Mohammad Hosseinpur was born in Tabriz, Iran in 1979. He is currently a Ph.D. candidate in TEFL at Allame Tabatabaii University. He holds an M.A. in TEFL from University of Tehran (2005) and a B.A. in English Literature from Allame Tabatabaii University (2002).

$\mathrm{He}$ is a faculty member of Qom University. He has over 10 years' experience of working as an EFL practitioner. His research areas include second language writing pedagogy, interlanguage pragmatics, and teaching methods. 